\title{
O FUNCIONAMENTO DE IMAGENS E A PRODUÇÃO DE SENTIDOS NA LEITURA DE TEXTOS DE RELATIVIDADE RESTRITA
}

Leandro Londero ${ }^{1}$

RESUMO: A partir da constatação básica de que imagens têm estado presentes e são relevantes em textos escritos, esta pesquisa objetivou: analisar como imagens participam das interpretações de licenciandos em física quando esses leem textos de divulgação científica sobre Relatividade Restrita. Para tanto, desenvolvemos uma pesquisa numa disciplina da Licenciatura em Física. Promovemos, sob determinadas condições de produção, a leitura por um conjunto de alunos em formação inicial de textos relacionados aos objetivos da pesquisa. O principal apoio teórico foi a análise do discurso iniciada na França por Michel Pêcheux. As imagens desempenharam um papel fundamental na produção de sentidos. Elas não foram vistas, em geral, como simples ilustrações, ou seja, não foram ocorrências sem importância, mostradas acidentalmente e utilizadas para atrair e agradar o leitor. Os sentidos produzidos para imagens comumente utilizadas nas produções textuais sobre a Relatividade Restrita são distintos para diferentes leitores/observadores. Elas envolvem relações históricas, sociais e pedagógicas também distintas entre produtores e leitores/observadores.

Palavras-chave: Imagens, Relatividade Restrita, Análise de Discurso, Ensino de Física.

\section{THE OPERATION OF IMAGES AND THE PRODUCTION OF MEANINGS IN READING RELATIVITY TEXTS}

ABSTRACT: From the basic evidence that images have been present in written texts and are relevant to them, this research aimed: to analyze how pictures take part into Physics pre-teachers understanding when they read scientific dissemination texts on restrict relativity. For that, we carried out a research in a discipline from a teacher education course in Physics. We promoted, under certain production conditions, the reading by a group of students in education course of texts related to the purposes of this research. The main theoretical framework was the discourse analysis initiated in France by Michel Pêcheux. In our study, the pictures developed an essential role in the meanings production. They were not considered, in general, as simple illustrations, it means, they were not occurrences without importance, showed accidentally and utilized in order to attract and please the reader. The meanings produced from the pictures commonly used in text productions upon restrict relativity are distinct to different readers/observers. They involve historic, social and pedagogical relations also distinct between producers and readers/observes.

Keywords: Picture, Relativity, Discourse Analysis, Physics Education.

\footnotetext{
${ }^{1}$ Doutor em Educação pela Universidade Estadual de Campinas (UNICAMP), Professor Assistente Doutor do Departamento de Educação, do Instituto de Biociências, Letras e Ciências Exatas da Universidade Estadual Paulista "Júlio de Mesquita Filho", campus de São José do Rio Preto. Orientador no Programa de PósGraduação em Educação para a Ciência, da Faculdade de Ciências da Universidade Estadual Paulista "Júlio de Mesquita Filho", campus de Bauru. Líder do grupo de pesquisa "Equipe de Educação em Física "Susana Lehrer de Souza Barros". E-mail: leandro.londero@unesp.br
} 


\section{CONSIDERAÇÕES INICIAIS}

Imagens podem ser consideradas como um importante recurso a ser levado em consideração no momento da elaboração de um texto. Entretanto, podemos acreditar no ditado "Uma imagem vale mais do que mil palavras"? Segundo Sicard (2000, p.25) "a ciência, a medicina criam imagens em grande número. [...] Quando as recebemos, elas deslocam nossas posições diante de objetos do mundo, dos outros e de nós mesmos."

Quando se trata da elaboração de um texto destinado à divulgação de um conceito ou teoria o cuidado na escolha/seleção das imagens que serão utilizadas deve ser redobrado, pois elas podem levar a interpretações errôneas sobre o assunto que é divulgado.

Se folhearmos as páginas de livros didáticos encontramos uma quantidade significativa de imagens. No entanto, é de estranhar que, pelo menos em determinadas situações, uma imagem (como uma palavra) por si só não signifique nada (WITTGENSTEIN, 1958). Alguém, por exemplo, poderia perguntar: Qual é o conteúdo da imagem na Figura 1 ? Qual é o seu significado?

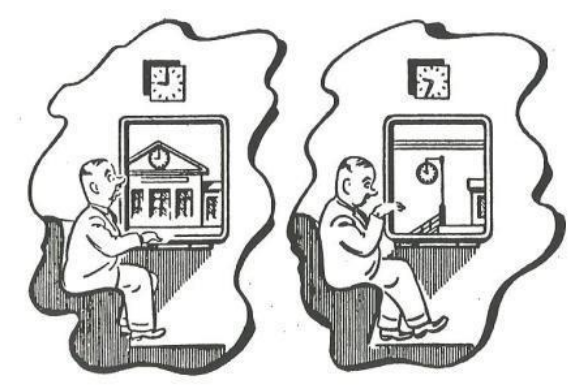

Figura 1 - Reproduzida de Landau e Rumer (1963)

Isolada, e às vezes, inclusive, acompanhada de um texto explicativo, a imagem, assim como os textos, pode ser, em momentos específicos, negligenciada em seu valor interpretativo, porque pode dar origem a diferentes interpretações dependendo das leituras anteriores de quem a interpreta. Como a leitura de um texto, a leitura de imagens está associada à história de outras interpretações. Albert Einstein em carta enviada a Jacques Hadamard e publicada em um livro deste último mencionava:

As palavras ou a linguagem escrita ou falada, não creio que desempenhem nenhum papel no mecanismo de meu pensamento. Os entes físicos que parecem servir de elementos ao pensamento são certos signos e certas imagens mais ou menos claras que podem ser 'voluntariamente' 
reproduzidas e combinadas (HADAMARD, 1945, p. 131).

No entanto, ao mesmo tempo que Einstein dá ênfase a certos signos e imagens, ele utiliza, em uma de suas principais obras "A teoria da relatividade especial e geral", somente uma imagem, que reproduzimos na figura 02 .

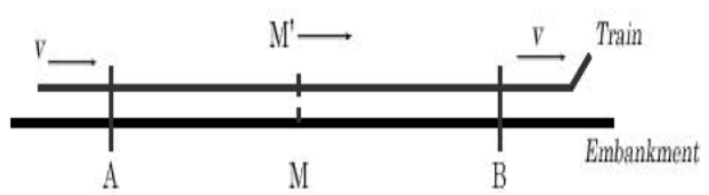

Figura 2 - Reproduzido de Einstein (1999)

Nesta pesquisa partimos do pressuposto que, quando imagens são incluídas nos textos, a produção de sentidos por quem os lê estará associada ao funcionamento das imagens que os constituem. Assim, ao assumirmos que a utilização de imagens tem estado presente e é relevante em textos escritos, objetivamos analisar de que maneira as imagens participaram das interpretações de um licenciando em física quando este leu textos de divulgação científica sobre relatividade restrita, escritos por cientistas.

Em função desse objetivo, embora tenhamos realizado a coleta de informações com vários estudantes de uma turma de Licenciatura em Física, neste texto, dado o amplo espectro de significados que pudemos notar nas interpretações de diferentes estudantes, optamos por detalhar as interpretações realizadas por um deles visando uma compreensão abrangente das suas interpretações. É fato que grande parte dos estudos destinados ao estudo de imagens se apoiam em diferentes vertentes da Semiótica. Entretanto, neste estudo, estamos considerando as imagens como um tipo de discurso. Souza (2001) esclarece que:

O estudo de imagens, como discurso produzido pelo não-verbal, abre perspectivas comumente não abordadas em análises mais recorrentes. Abre-se a possibilidade de entender os elementos visuais como operadores de discurso, condição primeira para se desvincular o tratamento da imagem através da sua correlação com o verbal e de se descartarem os métodos que "alinham o verbal pelo não-verbal (p. 93).

Nesse sentido tendo em conta que tanto textos didáticos quanto os de divulgação científica sobre a Teoria da Relatividade Restrita apresentam várias imagens: trens, réguas, relógios e gêmeos, admitimos a relevância de compreender o funcionamento dessas imagens nas interpretações de estudantes de física ao lerem textos sobre 
relatividade, escritos por cientistas.

Ao longo dos anos verifica-se a utilização crescente de recursos visuais como gráficos, tabelas, fotos e outras ilustrações específicas inseridas nos textos por meio de referências e de legendas explicativas. Na perspectiva de Martins et al. (2005), imagens são importantes recursos para a comunicação de ideias científicas. Segundo as autoras, além da indiscutível importância como recurso para a visualização, contribuindo para a inteligibilidade de diversos textos científicos, as imagens também desempenham um papel fundamental na constituição das ideias científicas e na sua conceitualização. Por outro lado, alguns autores apontam para os cuidados que se deve ter ao usar imagens (FREITAS, 2002; CASSIANO, 2002, SILVA et al., 2006).

Um ponto importante destacado por Martins et al. (2005) é que essas questões têm sido objeto de um crescente conjunto de investigações no campo da Educação em Ciências por pesquisadores que compartilham o interesse de melhor compreender as relações entre imagens, conhecimento científico e Ensino de Ciências.

A escolha, especificamente, da relatividade pode ser justificada não apenas por sua relevância no âmbito da Física Moderna e Contemporânea, mas também pelo fato do físico alemão Albert Einstein (1879-1955) se destacar não somente como um grande cientista e uma figura da nossa cultura, mas principalmente por preocupar-se, ao longo de sua vida, em divulgar o conteúdo de suas teorias, tanto para o público especializado quanto para o leigo.

\section{AS IMAGENS NO ENSINO DE FÍSICA}

Os livros são materiais muito utilizados no ensino escolar. Em especial, na Educação em Ciências, eles são amplamente utilizados. Tendo em vista que neles encontramos muitas imagens, é esperado que esse fato atraia a atenção de educadores em ciências, preocupados com o potencial das imagens enquanto recurso de construção de significados.

Ao investigar o uso pelos docentes de imagens em livros didáticos de Física, Silva (2008) mostrou que, de maneira geral, havia uma qualidade visual muito boa, coexistindo de forma harmônica a linguagem verbal e a não-verbal. Entretanto, os resultados obtidos revelaram a falta de uso de diferentes linguagens pelos docentes no trabalho em aula, 
principalmente com a visual, revelando um descompasso entre as instituições educacionais e os meios de comunicação cujo domínio da transmissão de informação tem sido a comunicação visual. O autor relata a necessidade de capacitação docente para utilização adequada da linguagem visual em sala de aula, mediante a exploração de imagens com diferentes graus de iconicidade (abstração).

A análise de imagens em livros didáticos de física também foi objeto de estudo de Cassiano (2002). Entre os resultados obtidos, Cassiano menciona a importância da imagem na transmissão dos conceitos físicos, via texto didático, uma vez que as representações visuais têm forte presença nos livros didáticos de física analisados. No entanto, segundo o autor, em nenhuma obra analisada no estudo há preocupação de orientar o professor no uso das imagens como apoio didático e complemento à explicação textual.

Para Cassiano, as imagens, na sua dimensão pedagógica, não podem ser vistas apenas como "figuras que embelezam e ajudam a vender um livro", mas como forma de linguagem que pode contribuir para a aprendizagem de conceitos científicos e para a otimização da dinâmica de comunicação em sala de aula.

Silva (2002) analisou como e que sentidos foram produzidos na leitura de imagens e textos que funcionaram em situações de ensino que compuseram uma unidade sobre gravitação newtoniana. $\mathrm{O}$ autor relata que a análise dos processos discursivos em torno da síntese newtoniana revelou que as imagens podem funcionar produzindo sentidos que compõem uma perspectiva ampla de formação cultural pela educação científica, incluindo a própria prática de leitura nesta formação.

Zimmermann e Evangelista (2004) relataram uma análise das interpretações de imagens de um livro didático feitas por dez alunos de uma escola de Brasília. O estudo revelou que: os alunos não conseguem interpretar os elementos representados em imagens, sejam eles reais e esquemáticos ou entidades simbólicas; é necessário, sobretudo no caso de esquemas, que haja a interferência do professor para que o aluno perceba e interprete os elementos presentes; os alunos tendem a fazer uma descrição dos elementos reais da imagem, não se atendo a esquemas, setas, símbolos etc. Para interpretar uma dada imagem, os alunos tendem a buscar conhecimentos teóricos anteriores ou do seu dia-a-dia; eles apresentaram dificuldade para interpretar imagens que necessitavam de uma interpretação de relações entre diferentes ícones imagéticos.

Silva e Martins (2008) investigaram a iconicidade em livros didáticos de física. As 
autoras observaram projetos gráficos diferenciados entre os livros analisados, caracterizando propostas semelhantes, contendo imagens variadas com diferentes graus de iconicidade, sendo que a escolha do tipo de ícone depende da sua consonância com as informações apresentadas e com o estímulo pretendido.

Carmo et al. (2000) investigaram as distorções conceituais presentes no experimento do calorímetro de pás, realizado por Joule. Segundo estes autores, os textos sobre o experimento associado às figuras do calorímetro, em geral incompletas, simplificam-no em demasia, desconsiderando a real complexidade e todas as dificuldades enfrentadas por Joule na execução do experimento. Os autores concluíram que: "longe, portanto, de auxiliarem na compreensão deste importante e complexo experimento, 'crucial' para o desenvolvimento subsequente da Termodinâmica, os livros utilizam as representações visuais como meros aspectos ornamentais, por vezes belo e mesmo coloridos, sem emprestarem aos mesmos, entretanto, os significados funcionais que poderiam desempenhar na apresentação daquele conteúdo" (CARMO et al., 2000, p. 14).

No que tange às funções das representações visuais em situações de sala de aula de Ciências, Martins (1997) desenvolveu um estudo de caso em escolas secundárias de Londres e analisou livros didáticos. A autora revela que havia uma crescente utilização de imagens e recursos gráficos e constatou uma mudança na relação texto-imagem. Nos textos tradicionais a mensagem principal vinha na forma de texto escrito e as imagens possuíam a função quase que exclusiva de ilustrar ou auxiliar a visualização, fornecer detalhes, enriquecer ou tornar o texto mais interessante ou atrativo. As ilustrações eram subordinadas ao texto. Já os textos modernos mostravam tendência oposta. Foi possível encontrar exemplos nos quais o texto escrito apenas dava nome a algo definido de maneira gráfica, ou possuía a função de comentário ou sugestão de como o 'visual' deveria ser lido. Em alguns casos, o 'visual' era, de fato, o principal meio de comunicação (MARTINS, 1997, p. 295).

Com relação aos alunos, a autora destaca que as primeiras reações se referiam à estética das imagens ("gosto", "não gosto", "fica bonito"), sugerindo um engajamento inicial via canal afetivo. Em seguida, evoluíam para comentários acerca de elementos de composição (como a cor usada), e podiam chegar mesmo a julgamentos se determinada representação seria útil ou não para a aprendizagem. Os alunos também fizeram distinção entre imagem "científica" e "não-científica", considerando gráficos e diagramas científicas. 
Por sua vez, as histórias em quadrinhos e fotografias foram consideradas "não-científicas".

Martins et al. (2005) relataram resultados de uma investigação sobre como as imagens presentes em livros didáticos de ciências eram lidas e compreendidas por estudantes. Suas respostas mostraram que as imagens não são transparentes e suscitam diferentes interpretações e entendimentos. Na busca de uma significação para as imagens os alunos se engajaram em procedimentos elaborados que envolviam análises de elementos composicionais.

Dib et al. (2003) tiveram como foco principal os significados que os alunos atribuíam às imagens que ilustram um texto didático. A análise mostrou que, apesar dos estudantes atribuírem significados variados às imagens, ao escolherem as fotografias para ilustrar o texto em questão buscaram identificar os elementos comuns entre as duas formas de linguagens. Isso os levou a escolher as mesmas imagens que, originalmente, já faziam parte do texto.

Bernuy et al. (2000) analisando livros didáticos de ciências e de física, apontaram que imagens não são apenas ilustrações subordinadas aos textos escritos, mas constituem-se também no conteúdo do texto propriamente dito e constataram um crescente uso das imagens e a crescente variedade destas nos livros didáticos, assim como uma grande complexidade de suas estruturas visuais.

Recentemente, Souza et al. (2010) publicaram um artigo de revisão de literatura, intitulado "A imagem em artigos publicados no período 1998-2007 na área de Educação em Ciências", no qual sintetizam a análise de um conjunto de estudos sobre imagens. As autoras relataram um aumento significativo de artigos publicados sobre imagens ao longo do período analisado.

A partir do breve relato de algumas pesquisas com foco no estudo das imagens, foi possível constatar que uma parte considerável dos estudos possui como objeto de investigação o livro didático. O complicador é que as imagens podem valer por mil palavras, mas como outros recursos podem também significar muito pouco.

\section{APOIO TEÓRICO}

Utilizei como apoio teórico a Análise do Discurso (AD), com a intenção de questionar como os significados atribuídos às imagens haviam sido produzidos. $A A D$, na 
vertente iniciada nos anos sessenta do século passado, na França, com o trabalho de Michel Pêcheux, tem na sua origem no questionamento da linguagem considerada como transparente. Nessa linha de pensamento, ela não se limita a mero instrumento para comunicação de informações, nem é apenas um meio para se pensar (ALMEIDA, 2007).

Orlandi (2003) ressalta que alguns aspectos devem ser considerados: o sujeito; a linguagem e seu processo histórico; os dispositivos de análise; as condições de produção, entre outros.

Na $A D$, o discurso é uma construção social, não individual, e que só pode ser analisado considerando seu contexto histórico-social, suas condições de produção. Ele supõe uma visão de mundo determinada, necessariamente, vinculada à dos seus autores e à sociedade em que vivem.

Em nosso estudo, analisamos os discursos de um estudante de licenciatura em física no que diz respeito ao funcionamento de imagens, a partir da leitura que ele realizou de textos de divulgação sobre a Teoria da Relatividade Restrita escritos por cientistas. Assim, tornou-se fundamental termos um entendimento das condições de produção para a leitura, seja ela dos textos lidos ou das imagens. Em Orlandi (2003) encontramos que as condições de produção

[...] compreendem fundamentalmente os sujeitos e a situação. Também a memória faz parte da produção do discurso [...]. Podemos considerar as condições de produção em sentido estrito e temos as circunstâncias da enunciação: é o contexto imediato. $E$ se as consideramos em sentido amplo, as condições de produção incluem o contexto sócio-histórico, ideológico (...) E, finalmente, entra a história [...]. Todos esses sentidos já ditos por alguém, em algum lugar em outros momentos, mesmo muito distante [...] (p. 30-31)

A leitura, considerada como produtora de sentidos, está regulada por condições de produção (ORLANDI, 1988). Mas dado que o texto, em relação ao leitor e também ao autor, é uma produção inacabada, incompleta, já que sempre são possíveis novas leituras, novos sentidos, que estão relacionados com as condições de produção da nova leitura possível, faz-se necessário levar em conta essas condições de produção, que permitam compreender essas outras leituras (MICHINEL, 2001).

Para Orlandi (1998), a leitura entendida como produtora de significado depende da história de leitura da pessoa, e, como toda pessoa tem uma história de leitura, isto 
condiciona que um texto seja lido de uma maneira e não de outra em relação a leituras anteriores.

Tal como Michinel (2001), recorremos à AD para fazer emergir as interpretações que no processo poderiam estar se produzindo. Caracterizamos assim discursos e identificamos possíveis maneiras como se produzem.

\section{AS CONDIÇÕES DE PRODUÇÃO DA COLETA DE INFORMAÇÕES, LOCAL DE REALIZAÇÃO E SUJEITOS}

A pesquisa aqui relatada proporcionou, em aulas de uma disciplina da Licenciatura em Física, a leitura de textos de autores cientistas, com foco na teoria da relatividade restrita. Embora o nosso propósito neste artigo seja o de detalharmos a análise apenas de discursos de um estudante, das aulas ministradas pelo primeiro autor deste artigo, participaram 16 alunos.

Assim, colocamos em funcionamento uma série de textos para a leitura e discussão pelos alunos, como condição de produção imediata. Os textos objeto da pesquisa foram distribuídos em um conjunto de oito encontros com duas aulas de 50 minutos cada um.

No primeiro dia de aula, após a apresentação dos alunos e do docente pesquisador, aplicamos um questionário com o objetivo de obtermos algumas informações sobre os estudantes e sobre como interpretavam até aquele momento alguns aspectos da prática didático-pedagógica. Informamos, também, que daríamos ênfase ao ensino da Relatividade Restrita, portanto, ao final desses oito encontros os alunos teriam que entregar um episódio de ensino, elaborado para o nível médio, sobre esse tópico. No quadro 1 apresentamos as referências utilizadas em cada encontro.

\begin{tabular}{|c|c|c|}
\hline Aula & Assunto & Texto Base \\
\hline $1^{\mathrm{a}}$ & Organização da disciplina & --- \\
\hline $2^{\mathrm{a}}$ & Ensino da Relatividade Especial no Ensino Médio & $\begin{array}{ll}- & \text { Renn (2004) } \\
\text { - } & \text { Karam et al. (2007) } \\
\end{array}$ \\
\hline $3^{\mathrm{a}}$ & $\begin{array}{l}\text { O Uso de Imagens no Ensino de Ciências; Ensino da Relatividade } \\
\text { Especial no Ensino Médio }\end{array}$ & $\begin{array}{l}\text { - Martins el al. (2005) } \\
\text { - Guerra el al. (2007) }\end{array}$ \\
\hline $4^{a}$ & $\begin{array}{l}\text { O Uso de Imagens e o Ensino da Teoria da Relatividade no } \\
\text { Ensino Médio }\end{array}$ & $\begin{array}{l}\text { - Andrade et al. (2005) } \\
\text { - Silva et al. (2006) }\end{array}$ \\
\hline $5^{a}$ & $\begin{array}{l}\text { O uso de textos de divulgação de autores cientistas para o } \\
\text { ensino da Relatividade Especial }\end{array}$ & $\begin{array}{l}\text { - Silva (2006) } \\
\text { - Landau e Rumer (1963) }\end{array}$ \\
\hline $6^{\mathrm{a}}$ & $\begin{array}{l}\text { O uso de textos de divulgação de autores cientistas para o } \\
\text { ensino da Relatividade Especial }\end{array}$ & - Einstein e Infeld (1966) \\
\hline $7^{\mathrm{a}}$ & O uso de textos de divulgação de autores cientistas para o & - Coleman (1950) \\
\hline
\end{tabular}




\begin{tabular}{|l|l|l|}
\hline & ensino da Relatividade Especial & \\
\hline $8^{\mathrm{a}}$ & $\begin{array}{l}\text { Apresentação e entrega do episódio de ensino enfocando "Algumas Raízes e Consequências da } \\
\text { Relatividade" }\end{array}$ \\
\hline
\end{tabular}

Figura 3 - Quadro com as condições de produção imediatas da disciplina. Fonte: o autor

A cada aula, solicitávamos aos alunos a leitura extraclasse dos textos selecionados para o encontro seguinte, visando a discussão dos aspectos principais, bem como suas dúvidas. Elaborávamos, com antecedência, algumas questões que consideramos de aquecimento, para estimular os participantes a acompanharem a apresentação realizada pelo professor-pesquisador e a participarem do debate coletivo.

Elaborávamos também apresentações com sínteses do assunto abordado. Além disso, o professor-pesquisador coordenava as discussões no debate coletivo, de modo a garantir, ao máximo, a contemplação de questões trazidas pelos estudantes.

Também solicitávamos respostas escritas para algumas questões que deveriam ser devolvidas ao professor-pesquisador. Estas eram tabuladas e apresentadas aos estudantes na aula seguinte.

Realizamos a vídeo gravação das aulas nas quais desenvolvemos atividades de leitura e discussão de imagens. As filmagens centralizaram-se no professor-pesquisador, em atividade docente junto aos alunos, e nas participações deles na realização das atividades propostas, com o intuito de registrar os discursos proferidos pelos estudantes em relação ao funcionamento das imagens. Também foi recolhido ao final da disciplina, de 15 aulas, o Episódio de Ensino sobre Relatividade Restrita, elaborado pelos estudantes.

Neste artigo o foco de análise concentra-se nas interpretações do estudante Carlos, com atenção especial ao papel que elementos das condições de produção da disciplina exerceram.

\section{AS INTERPRETAÇÕES DO ESTUDANTE CARLOS}

Consideramos importante compreender as interpretações de alguns licenciandos, percorrendo as produções destes estudantes ao longo do desenvolvimento de todo o nosso estudo. Neste artigo, apresentaremos, especificamente, as posições do estudante Carlos nas atividades solicitadas, procurando compreender os sentidos atribuídos por ele, no que tange ao funcionamento de imagens na leitura da relatividade restrita. Optamos por apresentar as interpretações de Carlos em virtude de sua grande participação nas 
atividades de sala de aula.

Orlandi (2006) esclarece que a noção de interpretação passa por ser transparente quando na realidade são muitas e diferentes suas definições. Segundo ela, a interpretação está presente em toda e qualquer manifestação da linguagem. Não há sentido sem interpretação, ou seja, interpretar é atribuir sentidos. Ao analisarmos os discursos proferidos estamos procurando compreender os sentidos atribuídos pelos sujeitos.

Primeiramente, perguntamos para Carlos como funcionam as imagens/ilustrações/figuras enquanto recursos de ensino e como elas deveriam funcionar no caso específico de conteúdos de física? Ele deveria justificar sua resposta, se possível dar exemplos e respondeu:

Creio que elas têm um carácter motivacional e podem gerar bons debates. É comum observar jornais que trazem tiras, charges e quadrinhos a respeito de cientistas ou conceitos da ciência (C).

Como comentado por Carlos, tiras, quadrinhos e charges estão quase sempre presentes no dia a dia, em jornais, revistas, outdoors, além de provocarem o humor. Notamos, nesse estudante, uma predisposição ao uso de diferentes tipos de linguagem no ensino. No seu discurso ele aponta a motivação como elemento que justificaria o uso de charges e quadrinhos, além da possibilidade de debate.

Na segunda aula adentramos, especificamente, em nosso estudo. Ao final da aula, solicitamos aos estudantes que escolhessem ao menos três imagens que utilizariam para explicar assuntos/conceitos de relatividade restrita. A questão foi: Se você fosse utilizar uma imagem para ensinar um assunto/conceito de relatividade restrita, qual imagem você escolheria/selecionaria? Justifique sua escolha e exponha os critérios que utilizou para a seleção. A primeira imagem escolhida por Carlos é reproduzida na figura 3. 

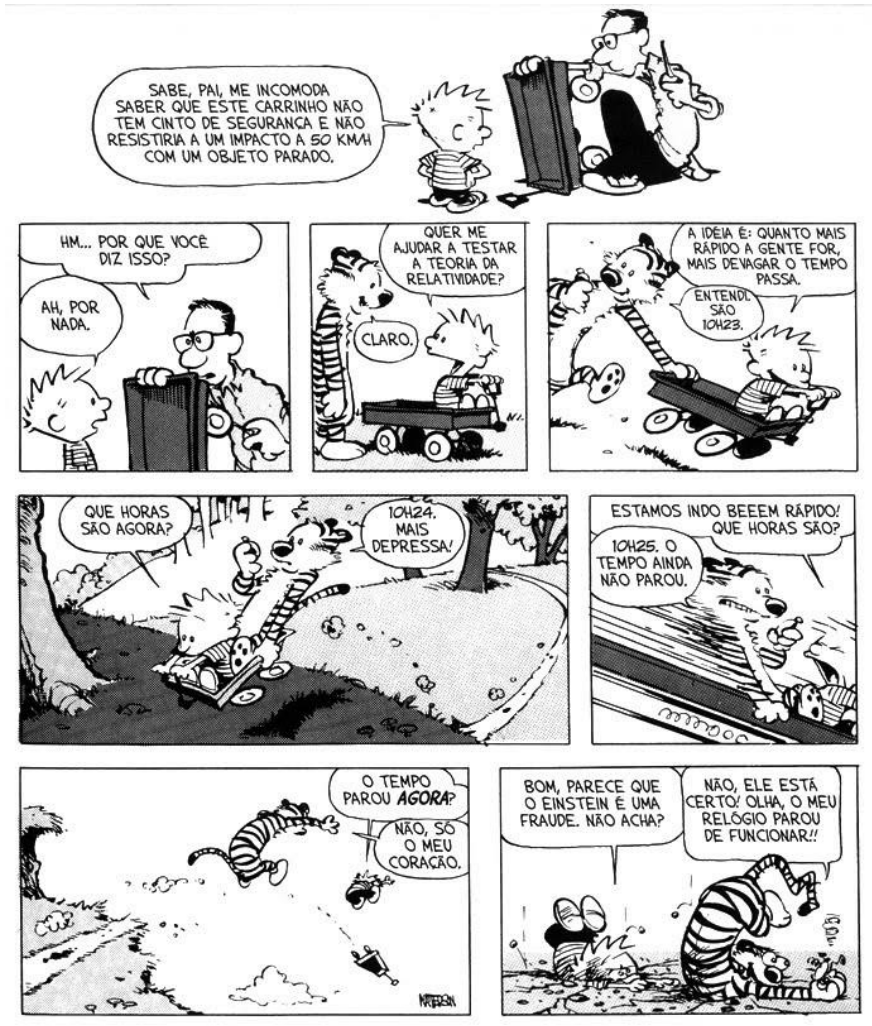

Figura 4 - Primeira imagem escolhida por Carlos. Disponível em: http://juarezdc.blogspot.com/2011/01/calvin-eharoldo.html?view=snapshot

A justificativa para a escolha da imagem foi a seguinte:

Creio que esta tirinha é uma maneira bem viável de começar o assunto de relatividade no ensino médio, visto que a curiosidade dos alunos seria aguçada pelo humor, e o conceito de relatividade seria menos complicado de ser passado, já que é uma área da física bem difícil de ser compreendida pela maioria das pessoas (C).

No discurso acima, notamos aspectos já mencionados nas respostas ao questionário inicial, ou seja, a sua tendência para o uso de tiras/Histórias em Quadrinho. Essa posição aparece recorrentemente em seu discurso. Para Carlos o humor facilita "passar" o conceito de relatividade. No imaginário desse estudante, conceitos podem ser "passados" e que o humor seria um recurso facilitador dessa "passagem".

O estudante preocupa-se em aguçar a curiosidade dos alunos e, para ele, uma possível maneira seria via efeito humorístico, com o uso de tiras. Ainda, "o conceito de relatividade seria menos complicado de ser passado, já que é uma área de física bem difícil de ser compreendida pela maioria das pessoas". Talvez o trecho final de seu discurso possa estar relacionado com sua própria experiência quando de seu contato com o tema.

Aparentemente, sua primeira escolha está pautada pelo público ao qual a imagem 
irá se destinar, talvez por isso ele escolheu uma História em Quadrinho, tal como discursou anteriormente pronunciando "o elemento usado está ligado ao público que se deseja atingir". Por outro lado, cabe ressaltar a possibilidade não considerada por ele de que o humor possa não funcionar da mesma maneira para todos os alunos. A segunda e a terceira imagens escolhidas são apresentadas na sequência.
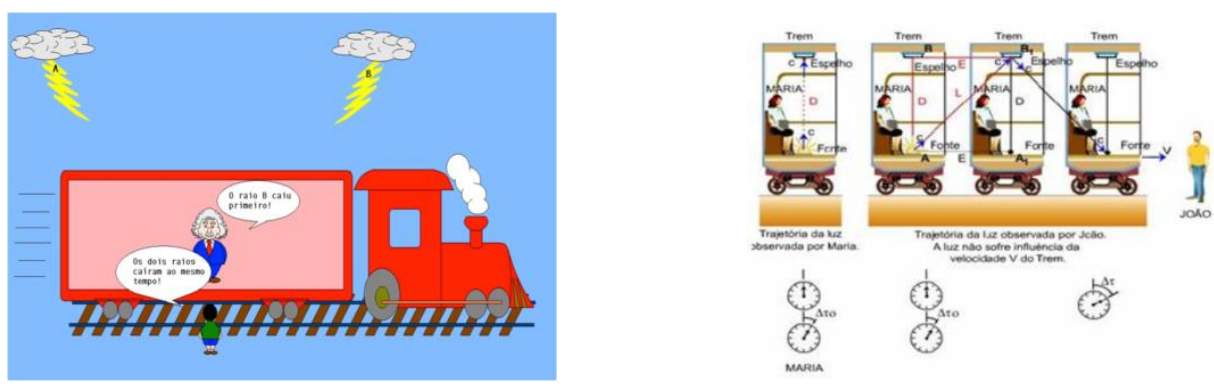

Figuras 5 e 6 - Segunda e terceira imagens escolhidas por Carlos

Como justificativas para a seleção das imagens o estudante argumentou:

Na teoria de Einstein, o tempo de um observador se dilata em relação a outro. E para mostrar como isso ocorre deve-se entrar antes no conceito de simultaneidade. A melhor forma de apresentar o caráter relativístico é através do clássico exemplo, onde temos um vagão de trem que é atingido por dois raios $A$ e $B$, respectivamente. Sendo nesse momento onde aparece a figura para podermos explicar a simultaneidade (C).

Depois de apresentado os conceitos de simultaneidade entramos na dilatação do tempo, retornamos ao exemplo do trem, no qual Maria viaja observada por Pedro, que está parado na plataforma e através da figura verificar que a dilatação do tempo depende do referencial de observação, tendo aí um tempo próprio e tempo dilatado, e mostrando aos alunos que o tempo não é mais absoluto como era proposto pela mecânica newtoniana (C).

Basicamente essas seriam as figuras principais para podermos explicar a teoria da relatividade restrita, sem muitas dificuldades. Uma vez que se o professor dispuser apenas de um quadro com giz, não terá dificuldades de estar ilustrando-as. Caso o professor dispor de recursos como Data Show pode "brincar" mais um pouco as imagens e simulações para ajudar o aluno a visualizar a compreender os conceitos físicos envolvidos (C).

Na segunda imagem, Carlos inicialmente expõe o conteúdo a ser discutido (dilatação do tempo). Ele considera a necessidade de se conhecer a noção de simultaneidade, apresentando em seguida a imagem a ser utilizada para abordar esse 
conceito, qual seja "através do clássico exemplo, onde temos um vagão de trem que é atingido por dois raios $A$ e $B^{\prime \prime}$. Na sequência, ele mostra a terceira imagem que dará conta da discussão da dilatação do tempo, explicando o conteúdo nela presente.

O estudante enfatiza que "a melhor forma de apresentar o caráter relativístico é através do clássico exemplo, onde temos um vagão de trem que é atingido por dois raios $A$ e $B$, respectivamente". Ele atribui um sentido importante ao exemplo explicitado. Podemos inferir que esse exemplo foi mobilizado de sua memória discursiva. Davallon (2007) esclarece que:

[...] lembrar um acontecimento ou um saber não é forçosamente mobilizar e fazer jogar uma memória social. Há necessidade de que o acontecimento lembrado reencontre sua vivacidade; e sobretudo, é preciso que ele seja reconstruído a partir de dados e de noções comuns aos diferentes membros da comunidade social. (p. 25).

Para Carlos o exemplo do vagão de trem mostrou-se potencialmente útil para aprendizagem da Relatividade Restrita. O exemplo lembrado reencontrou vivacidade e se fez presente no seu discurso.

Na continuidade o estudante expõe: "Sendo nesse momento onde aparece a figura para podermos explicar a simultaneidade". Seria então a imagem operador da memória de Carlos? Por que a imagem?

Em Davallon (2007) encontramos uma resposta. Segundo ele, a imagem oferece ao menos em um campo histórico que vai do século XVII até nossos dias - uma possibilidade considerável de reservar a força: a imagem representa a realidade, certamente; mas ela pode também conservar a força das relações sociais (e fará então impressão sobre o espectador) (DAVALLON, 2007, p. 27).

Cabe aqui notar que, possivelmente, Carlos considera que a aprendizagem ocorrerá para outros indivíduos de maneira semelhante à que possivelmente ocorreu para ele, sem levar em conta que a leitura de imagens, como a leitura de textos, tem de ser aprendida.

Na terceira aula iniciamos o estudo das imagens discutindo o texto de Martins et al. (2005) e finalizamos com a produção de Guerra et al. (2007). Na quarta continuamos a discussão com o artigo de Silva et al. (2006) e de Andrade et al. (2005).

Com estes textos finalizamos a discussão teórica sobre imagens, sendo eles, as 
condições associadas às histórias de vida dos estudantes que poderiam interferir nos discursos que pudessem surgir a partir dessas aulas

Ao perguntarmos para Carlos como funcionam as imagens nos processos de ensino e de aprendizagem, ele respondeu

Funcionam como facilitadoras da visualização do objeto de estudo, se ganha tempo e qualidade sobre outra desenhada na lousa. Exigem menos esforço do aluno para imaginar uma situação, podendo focá-lo mais no objeto de estudo. Elas se aproximam da realidade da atual sociedade, bombardeada por imagens diversificadas: na TV, do vídeo game, da internet, de outdoors, de revistas, de propagandas etc, em contraponto à forma clássica de aula: leitura de texto, discussões, palestras etc, e ao cotidiano antigo: visão de objetos reais, rádio, etc. Em uma única imagem pode-se explorar vários tópicos, ajudam na questão da multidisciplinariedade (C).

Para ele, aparentemente, as imagens funcionam pela capacidade de representar, pela informação que podem oferecer. Ele não considera, nesse discurso, sua eficácia simbólica. Por outro lado, considera-as: "facilitadoras da visualização do objeto de estudo, se ganha tempo e qualidade sobre outra desenhada na lousa. Exigem menos esforço do aluno para imaginar uma situação". Davallon (2007) já argumentava que:

Com efeito, aquele que observa uma imagem desenvolve uma atividade de produção de significação; esta não Ihe é transmitida ou entregue toda pronta. Esse estado de coisas abre, como aliás insistem em nos fazer observar, a uma liberdade de interpretação (o que quer dizer que o conteúdo "legível", ou antes "dizível", pode variar conforme as leituras); mas o que faz também - e não se poderia esquecer este ponto - com que a imagem comporte um programa de leitura: ela assinala um certo lugar ao espectador (ou melhor: ela regula uma série com a passagem de uma a outra posição de receptor no curso da recepção) e ela pode "rentabilizar" por si mesma a competência semiótica e social desse espectador (p. 29).

Concordamos com Davallon quando argumenta que ler uma imagem é atribuir significados que não podem ser transmitidos, mas dependem de uma interpretação, a qual, por sua vez, depende daquele que a interpretou, de sua história de leitura, de sua memória discursiva, entre outros aspectos, o que não foi levado em conta no discurso de Carlos. Por outro lado, uma evidência de que ele considera que as imagens ensinam pode ser notada quando fala do tempo que elas economizam. Além disso, nota-se que, para ele, o que o professor pode desenhar na lousa não seria uma imagem. Nota-se também que não pensa a imagem como parte de um texto, como algo a ser lido. 
Perguntamos, também, quais as características que uma imagem deveria possuir. A resposta de Carlos foi:

Independente do uso, ela não pode conter erros conceituais, fora isso, as características dependem muito do uso. Porém, alguns aspectos, em geral, são bastante desejáveis: ter legenda; estar num contexto adequado; ser colorida; desenho razoavelmente bem feito; boa centralização; focalização e contraste do objeto de estudo; indicação de escala ou possuir objetos conhecidos para comparar dimensões (C).

Na perspectiva de Davallon (2007, p. 30), existe uma espécie de aproximação entre as oposições formais (de forma, de cor e de topologia) e a instância textual e discursiva. 0 autor cita, por exemplo, o caso da publicidade, na qual certa relação de cor ou certo contraste de forma retém o olhar e, ao mesmo tempo, quer nos dizer da qualidade que distingue um produto dos outros.

Questionamos ao estudante se considerava que alguns assuntos de física são mais propícios ou necessitam mais a utilização de imagens. Solicitamos justificativa e, em caso positivo, quais conteúdos destacaria. Também interrogamos qual a importância que atribui às imagens no ensino de conteúdos de física. As respostas de Carlos foram:

Acho que todos os conteúdos são melhores trabalhados com imagens $e$ todos possuem bons potenciais de uso. Talvez assuntos cujos fenômenos são menos tangíveis demandem mais o uso de imagens (C).

Ajuda na observação de vários aspectos que integram um conceito, além de ajudar a torná-los mais "reais", mais "concretos", algo importante quando se introduz um novo conceito.

Ele destacou o uso de imagens para aqueles conteúdos que considera "menos tangíveis". Ao usar o termo "tangíveis", talvez esteja se referindo aos conteúdos de natureza microscópica. Para Carlos as imagens ajudam "na observação de vários aspectos que integram um conceito" e tornam estes mais "reais/concretos". Em seu imaginário aparentemente as imagens facilitariam na abstração.

Para a seguinte questão: $E$ se pensarmos no ensino de relatividade (que vocês terão que elaborar uma unidade de ensino)? Explique/Justifique sua resposta, a resposta e 
a justificativa de Carlos foram:

Poderia dizer, sem perda de generalidade que o ensino de ciências, em especial a física, é uma ciência inteiramente visual. Na relatividade, por exemplo, para falar de eventos simultâneos é indispensável o uso de imagens, lembrando que as imagens devem ser trabalhadas com cuidado uma vez que elas não são transparentes (C).

Notamos o argumento da indispensabilidade do uso de imagens no ensino, por exemplo, de eventos simultâneos. Destaque é dado ao cuidado no uso das imagens "uma vez que elas não são transparentes". Ao discutir sobre autoria e interpretação, Orlandi destaca:

Quando o sujeito fala, ele está em plena atividade de interpretação, ele está atribuindo sentido às suas próprias palavras em condições específicas. Mas ele o faz como se os sentidos estivessem nas palavras: apagam-se suas condições de produção, desaparece o modo pelo qual a exterioridade o constitui. Em suma, a interpretação aparece para o sujeito como transparente, como sentido lá (ORLANDI, 2006, p. 65).

Em relação a autoria, Orlandi esclarece:

[...] a função de autor é tocada de modo particular pela história: o autor consegue formular, no interior do formulável, e se constitui, com seu enunciado, numa história de formulações. O que significa que, embora ele se constitua pela repetição, esta é a parte da história e não mero exercício mnemônico. Ou seja, embora não instaure discursividade, produz, no entanto, um lugar de interpretação no meio dos outros. Esta é sua particularidade. O sujeito só se faz autor se o que ele produz for interpretável. Ele inscreve sua formulação no interdiscurso, ele historiciza seu dizer. Porque assume sua posição de autor (se representa nesse lugar), ele produz assim um evento interpretativo. $O$ que só repete (exercício mnemônico) não o faz (ORLANDI, 2006, p. 69).

A autora distingue três tipos de repetições, são elas: a) repetição empírica exercício mnemônico que não historiciza; b) repetição formal - técnica de produzir frases, exercício gramatical que também não historiciza; c) repetição histórica - a que inscreve o dizer no repetível enquanto memória constitutiva, saber discursivo, em uma palavra: interdiscurso.

Notamos que as condições de produção da disciplina exerceram influência na construção do discurso de Carlos, ao menos no que se refere ao cuidado no trabalho com as imagens, uma vez que ele remete para parte do discurso da produção de Silva et al. (2006). Podemos considerar seu discurso como repetição histórica, uma vez que ele se 
inscreve no repetível.

Em continuidade, perguntamos aos estudantes como eles pensavam que autores e professores deveriam utilizar imagens como recurso de ensino, no caso da relatividade, e as recomendações que indicariam para o uso de imagens nesse tópico. A resposta de Carlos foi

Acredito que o uso de imagens é indispensável como uma grande ferramenta de aprendizagem. Tomando o cuidado com a não transparência das imagens, de forma a deixar claro o objetivo do uso de determinada imagem para complementar o ensino de determinado conteúdo, não ficando apenas no caráter verbal (C).

Nesse discurso percebemos a apropriação de condições de produção da disciplina. Tal discurso, como já mencionamos, pode ser considerado como "repetição histórica", ou seja, quando há incorporação de sentido próprio do aluno à memória constitutiva, isto é, o aluno passa a assumir o discurso como seu: a autoria, nos termos de Almeida et al. (2008). Entretanto, Carlos parece considerar a imagem como complemento de outros tipos discursivos, situação não incluída em nenhum dos textos trabalhados na disciplina.

O último questionamento estava relacionado ao texto de Martins et al. (2005), as quais questionam a "transparência" das imagens, ou seja, desafiam a ideia de que as imagens comunicam de forma mais direta e objetiva do que as palavras. Perguntamos se o argumento apresentado pelas autoras poderia ser refletido para as imagens utilizadas na relatividade restrita como, por exemplo, as utilizadas por Landau e Rumer (1963) ou as trabalhadas em sala de aula. Carlos respondeu:

Sim, diferentemente do ditado, uma imagem não vale mais do que mil palavras. Não se pode analisar e definir um relâmpago apenas com imagens e desconsiderar uma boa explicação do movimento de elétrons, ou estudar difração apenas utilizando a imagem de um prisma e ignorar a Lei de Snell. Uma imagem dependendo de como o professor a exponha ou de como os alunos a interpretem pode ficar nos alunos ideias errôneas. Deve-se considerar o fato de que uma fotografia, por exemplo, representa somente um determinado instante, e não a representação do fenômeno como um todo em movimento (C).

Carlos concorda com o argumento apresentado pelas autoras verbalizando que "[...] diferentemente do ditado, uma imagem não vale mais do que mil palavras". É possível, entretanto que tenha concordado por pretender obter aprovação na disciplina. Entretanto, ele apresenta, ainda, dois exemplos para justificar sua concordância, 
questionando que uma imagem "representa somente um determinado instante, e não a representação do fenômeno como um todo em movimento". No que tange a segmentação, de acordo com Davallon (2007):

[...] a imagem teria assim capacidade para integrar os elementos que a compõem em uma totalidade. É por que compreenderíamos o sentido global antes de reconhecer a significação os elementos; e atingiríamos primeiro o efeito dessa integração; estaríamos sob o charme desse efeito formal, estético; toda imagem pareceria assim se apresentar como única origem dela mesma assim como de sua significação; e enfim, ela introduziria uma diferença de natureza, um salto qualitativo entre os componentes (os que a análise pode repertoriar) e ela mesma considerada em sua totalidade. (p. 29)

Após expormos as posições de Carlos sobre aspectos concernentes às imagens, apresentamos suas interpretações quanto ao seu funcionamento na leitura da relatividade restrita, a partir de textos de divulgação científica elaborados por cientistas.

Na quinta aula discutimos, primeiramente, o texto de Silva (2006) e, após, a obra de Landau e Rumer (1963). Iniciamos a discussão perguntando se as imagens presentes na obra de Landau e Rumer (1963) ajudaram a compreender o que o autor desejava explicar, e em que medida, ou seja, questionamos que contribuições as imagens utilizadas pelo autor trouxeram, para a leitura e compreensão da Relatividade Restrita. Carlos posicionou-se afirmando que:

Analisando todas as imagens do texto, posso dizer que essas contribuíram, ainda mais para o caso de imaginarmos uma leitura por um leigo, que não estaria acostumado a imaginar e fazer esses tipos de construções mentais das situações, já que em várias delas acabam fica difícil entender exatamente o que o texto quer dizer ou mostrar, e ainda mais, dependendo da pessoa, ela pode imaginar uma situação diferente da qual o autor se refere. Sendo assim, as imagens se fizeram necessárias para evitar, ou pelo menos, reduzir qualquer tipo de má interpretação por parte do leitor. Dependendo da situação até para um leitor não-leigo pode ficar difícil imaginar exatamente a situação descrita pelo texto, mas não foi o caso nessa leitura (C).

No imaginário que se tem sobre o ensino por meio de imagens o estudante destacou que elas podem contribuir para o entendimento do texto, em especial para o caso de um leitor leigo no assunto. Além disso, as imagens funcionariam como agentes nas construções mentais das situações expostas no texto de Landau e Rumer (1963), contribuindo para evitar/reduzir uma má interpretação por parte dos leitores. 
Pedimos para os estudantes identificarem e justificarem quais imagens destacariam como significativas, entre aquelas utilizadas por Landau e Rumer. As imagens destacadas por Carlos são reproduzidas a seguir.

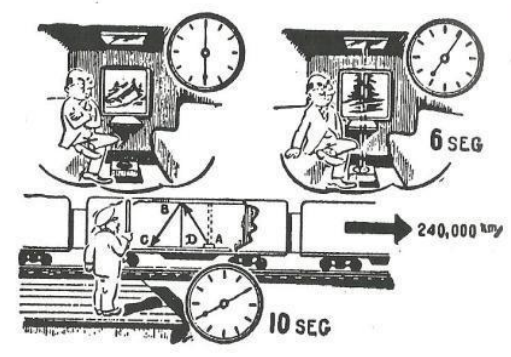

Figura 7 - Primeira imagem destacada por Carlos. Fonte: Landau e Rumer (1963)

A segunda imagem que aparece no texto ajuda a compreender a ideia de dilatação temporal no sentido de exemplificar como é a trajetória da luz para o passageiro dentro do trem e como ela é vista por alguém de fora do trem, essa diferença de percurso, somada a constância da velocidade da luz faz com que o tempo e o espaço se comportem de maneira diferente quando observados a altas velocidades (C).

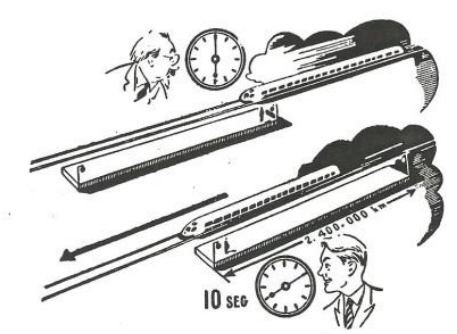

Figura 8 - Segunda imagem destacada por Carlos. Fonte: Landau e Rumer (1963)

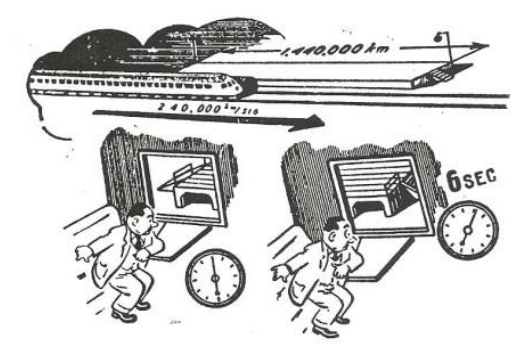

Figura 9 - Terceira imagem destacada por Carlos. Fonte: Landau e Rumer (1963)

As duas imagens localizadas nas páginas 92 e 93, respectivamente, são significativas para esclarecer que a medição, tanto do tempo quanto do comprimento depende do referencial em questão e varia de referencial para referencial de acordo com as transformações de Lorentz (C). 
A primeira imagem escolhida é a do triângulo isósceles. Carlos volta a selecionar a imagem que já havia escolhido na primeira atividade da disciplina. O estudante também destaca as imagens que no seu imaginário são significativas para explicar que a medição depende do referencial. Tendo em vista que as imagens estavam inseridas em um texto, podemos dizer que ambos contribuíram para a compreensão da mensagem transmitida pelos autores, como mencionou Carlos: "as imagens se fizeram necessárias para evitar, ou pelo menos, reduzir qualquer tipo de má interpretação por parte do leitor".

No sexto encontro, os estudantes já haviam lido os textos de Landau e Rumer (1963) e de Einstein e Infeld (1998). Após dialogarmos sobre a leitura da "A evolução da Física", perguntamos se a leitura dessa obra difere da leitura dos demais textos trabalhados e, em especial, da leitura de Landau e Rumer "O que é a teoria da relatividade?" Em caso positivo, em que aspectos os textos diferem? A resposta de Carlos foi:

Para um aluno de ensino médio o texto de Landau contém mais "desenhos" e menos gráficos, com uma linguagem mais simples e acessível, ilustrações bem colocadas, além de um toque de humor. Enquanto a obra de Einstein $e$ Infeld trata mais detalhadamente com uma abordagem mais epistemológica e linguagem sóbria a teoria da Relatividade, a obra de Landau e Rumer trata de maneira mais superficial, com muitas imagens e linguagem simples. Além disto, o próprio ponto de partida dos dois tratamentos são diferentes, sendo que a obra de Einstein leva em conta a invariância das equações de Maxwell frente às transformações de Lorentz, enquanto Landau/Rumer não menciona isto. (C)

O uso das palavras "desenho", "menos gráficos", "linguagem mais simples e acessível", "ilustrações bem colocadas", "toque de humor", parece indicar certo destaque para estas características que, no entendimento de Carlos, seriam mais apropriadas para um texto destinado a alunos do Ensino Médio, ou que contribuiriam para ensinar relatividade, caso o texto fosse utilizado com alunos desse nível básico.

Podemos supor que Carlos interpreta a obra, atribuindo sentido às próprias palavras, ao dar destaque a determinadas características linguísticas presentes nela. Por outro lado, as características destacadas aparecem como transparentes, ou seja, o estudante supõe que elas seriam plenamente compreendidas pelos alunos, uma vez que para ele elas o foram.

Em continuidade, na sétima aula, discutimos o livro "Relatividade para todos", de 
autoria de Coleman (1950). Ele foi escolhido por conter um conjunto significativo de imagens. Questionamos que contribuições as imagens utilizadas pelo autor trouxeram, para a leitura e compreensão da relatividade restrita e quais imagens destacariam como significativas entre aquelas utilizadas pelo autor. Reproduzimos, a seguir, as respostas de Carlos, com as imagens escolhidas e justificativas.

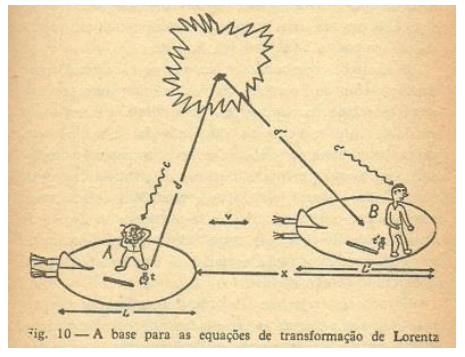

Figura 10 - Primeira imagem destacada por Carlos. Fonte: Coleman (1950)

Sim. Na realidade, sem a leitura textual, as imagens não podem ser completamente entendidas e apreciadas, por exemplo, a figura da página 121. Ela não é fácil de entender, é necessária a leitura, isso ocorre com todas as imagens praticamente (C).

Rego e Gouvêa (2010, p. 3) amparam-se em Bachelard (2005) para inferirem que “as imagens presentes em materiais didáticos para o ensino de Ciências apresentam particularidades relacionadas à finalidade de estabelecer conceitos científicos que, geralmente, diferem dos que os estudantes adquirem de sua experiência cotidiana com os fenômenos e objetos ao redor". Para as autoras

[...] faz-se necessário trabalhar com imagens que possuem alto grau de abstração e, consequentemente, pouca semelhança com a realidade conhecida por eles, mas que ajudem na construção de modelos que expliquem aspectos ou fenômenos da natureza, que possam ser generalizados e sirvam para uma aplicação tecnológica. A imagem ao perder em analogia e ganhar em abstração, admite funções de símbolos, em que são necessárias apropriações de convenções culturais elaboradas para o reconhecimento dos elementos que a compõem (p. 30).

Podemos dizer que, a primeira imagem citada por Carlos possui alto grau de abstração, uma vez que para ele "sem a leitura textual, as imagens não podem ser completamente entendidas e apreciadas". Ainda, para ele "Ela não é fácil de entender, é necessária a leitura, isso ocorre com todas as imagens praticamente". 
Tal como argumenta Rego e Gouvêa (2010), hoje, admite-se que, ambos, texto e imagem, exercem seu papel na leitura da mensagem que se quer transmitir, seja no entendimento do significado literal da mensagem e/ou na compreensão de sentidos para os quais o autor pretende dirigir o leitor. Neste sentido, estas autoras citam Schollhammer (2007) para quem:

A tradicional complementaridade entre palavra e imagem é hoje percebida com base na distinção das respectivas qualidades e deficiências de um e de outro meio de expressão. Às vezes a imagem é designada para 'ilustrar' a palavra, isto é, iluminar algo que se presume 'obscuro' no sentido imanente da palavra. Em outros casos, a palavra determina o sentido da imagem contra 0 poder sedutor da representação imediata. (SCHOLLHAMMER, 2007 apud REGO e GOUVÊA, 2010, p. 10)

Notamos, no discurso de Carlos, que a atribuição de sentidos se deu pela leitura texto/imagens. As outras imagens destacadas por Carlos são reproduzidas abaixo.

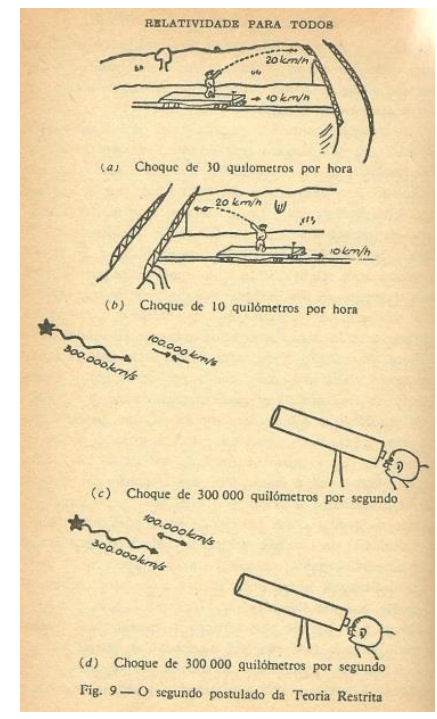

Figura 11 - Segunda imagem destacada por Carlos. Fonte: Coleman (1950)

As imagens mostram experimentos sobre a teoria galileana e a teoria da relatividade, mostra a diferença entre elas. São imagens completas e fáceis de entender. $O$ texto toma forma com as imagens simples. (C)

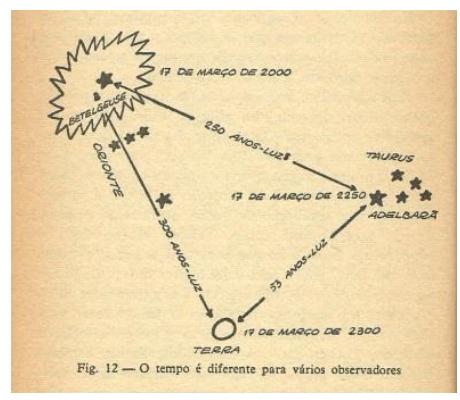


Figura 12 - Terceira imagem destacada por Carlos. Fonte: Coleman (1950)

Essa outra imagem ilustra mais um experimento. Também a achei bastante útil pois esclarece a ideia do texto sobre o tempo ser distinto para vários observadores. (C)

No que diz respeito à segunda e à terceira imagem, talvez para Carlos, elas tenham se mostrado menos abstratas do que a primeira, pois disse que: "São imagens completas e fáceis de entender. O texto toma forma com as imagens simples" e, "[...] bastante útil pois esclarece a ideia do texto [...]".

O uso da expressão "O texto toma forma" parece indicar que as imagens cumpriram um determinado papel nas explicações textuais realizadas pelo autor, ao menos na diferenciação entre a teoria galileana e a teoria da relatividade, bem como na explicação "[...]sobre o tempo ser distinto para vários observadores".

A última aula foi reservada para a apresentação e entrega do episódio de ensino, enfocando "Algumas Raízes e Consequências da Relatividade".

\section{CONSIDERAÇÕES FINAIS}

Durante a realização da pesquisa, foram observadas algumas imagens que aparecem de forma continuada para ilustrar a Relatividade Restrita como as de trens, réguas, relógios, gêmeos, plataformas, estações. Estas imagens apresentam sentidos que são produzidos de maneira distinta por seus leitores/observadores. Por envolverem relações históricas, sociais e pedagógicas também distintas entre produtores e leitores/observadores, elas acabam por afetar a maneira como lemos os textos e interagimos com eles, pois elas carregam padrões e crenças que lhes conferem poderes e que fazem com que elas sejam frequentemente utilizadas no ensino de relatividade.

A imagem do trem com o triângulo isósceles elucida uma simplicidade de cálculo. Isso parece certificar o estudante de que ela é transparente. É justamente a crença na transparência da imagem que faz com que ela seja facilmente manipulada e acabe sendo consumida na leitura e na sala de aula. Muitas vezes essa imagem é inclusive a parte central da explicação.

Os autores de livros de divulgação científica ao escolherem determinadas imagens acreditam estar motivando a leitura e/ou trazendo outros significados para o texto, os 
quais, por sua vez, tornam-se material de contato dos estudantes-leitores com as diferentes relações históricas e ideológicas presentes nas imagens. Ao priorizarem determinadas imagens, os autores consideram que os leitores estão acostumados com elas. A presença delas nos textos de relatividade é motivo de ligação entre o mundo em que o leitor vive e o contexto histórico no qual a relatividade surgiu e que o autor está tentando apresentar.

Por fim, dado o espaço de um artigo optamos por acompanhar o desempenho de um único estudante. Com ele, evidenciamos que, neste caso nossos resultados indicaram indícios de que as imagens desempenharam um papel relevante na sua produção de sentidos. Nos seus discursos elas não foram vistas, em geral, como simples ilustrações, ou seja, não foram ocorrências sem importância, mostradas acidentalmente e utilizadas para atrair e agradar o leitor. É importante reexaminar as suposições que as imagens produzem realidades distorcidas. Nosso estudo mostra que esse aspecto não parece ser válido para aquelas imagens presentes em textos de relatividade, pelo menos não com relação ao estudante analisado. Nos textos postos em funcionamento, podemos observar que as palavras e as imagens reforçam uns aos outros por meio de conexões.

Outro aspecto merecedor de destaque é que, as condições de produção para a leitura devem ser consideradas nas interpretações e nos possíveis sentidos produzidos pelos sujeitos leitores. E as relações entre palavras, imagens e outros recursos presentes nos textos devem ser vistos como interações dinâmicas.

A recorrência constante de imagens como as de trens, réguas, relógios, plataformas, gêmeos, em textos de relatividade, tanto didáticos quanto de divulgação científica, alerta para a necessidade de aprendermos a interpretar essas imagens. Por outro lado, acostumados a observá-las e a não refletir sobre elas, podemos acabar esquecendo que por trás da imagem está um produtor/autor e um contexto histórico.

\section{REFERÊNCIAS}

Almeida, M. J. P. M.; Souza, S. C.; Oliveira, O. B. (2008). Leitura e escrita em aulas de ciências: luz, calor e fotossíntese nas mediações escolares. Florianópolis: Letras Contemporâneas.

Almeida, M. J. P. M. (2007). Entrevista e Representação na Memória do Ensino de Ciências: uma relação com a Concepção de Linguagem. Nardi, R. (Org.). A Pesquisa em 
Ensino de Ciências no Brasil: Alguns Recortes. São Paulo: Escrituras.

Andrade, R.; Germano, M.; Nascimento, R. (2005). Influências da Teoria da Relatividade na Obra de Salvador Dali. XVI Simpósio Nacional de Ensino de Física, Rio de Janeiro.

Bernuy, A. A. C.; Martins, I. (2000). A compreensão dos estudantes sobre as imagens nos livros didáticos de Física para o ensino médio. VII Encontro de Pesquisa em Ensino de Física, Florianópolis.

Carmo, L. A., Medeiros, A., Medeiros, C. F. (2000). Distorções conceituais em imagens de livros textos: o caso do experimento de Joule com o calorímetro de pás. VII Encontro Nacional de Pesquisa em Ensino de Física, Florianópolis.

Cassiano, W. S. (2002). Análise de Imagens em Livros Didáticos de Física. Dissertação (Mestrado em Educação), UNB, Brasília.

Coleman, R. (1950). Relatividade para todos. Ulisseia.

Davallon, J. (2007). A imagem, uma arte de memória? Achard, P. et al. (Orgs.). Papel da Memória. Campinas: Pontes.

Dib, S. M. F.; Souza, J. R.; Carneiro, M. H. S. (2003). Textos e Imagens no ensino de ciências. IV Encontro Nacional de Pesquisa em Educação em Ciências, Bauru, SP.

Einstein, A. (1999). A Teoria da Relatividade Especial e Geral. Rio de Janeiro: Contraponto.

Einstein, A.; Infeld, L. (1966). A evolução da Física. Rio de Janeiro: Zahar.

Freitas, D. S. (2002). Imagens visuais nos livros didáticos de biologia do ensino médio: o caso do DNA. Tese (Doutorado) - FE, Unicamp.

Guerra, A., Braga, M., Reis, J. C. (2007). Teoria da relatividade restrita e geral no programa de mecânica do ensino médio: uma possível abordagem. Revista Brasileira de Ensino de Física, 29(4), 575-583.

Hadamard, J. (1945). Psychology of invention in the mathematical fiel. New York: Dover publications.

KARAM, R. A. S., CRUZ, S. M. S. C. S., COIMBRA, D. (2007). Relatividades no ensino médio: o debate em sala de aula. Revista Brasileira de Ensino de Física, v. 29, n. 1, p. 105- 114.

Landau, L.; Rumer, Y. (1963). O que é a Teoria da Relatividade. Editora MIR. (Série A Ciência ao Alcance de Todos).

Martins, I. (1997). O papel das representações visuais no ensino-aprendizagem de ciências. I Encontro de Pesquisa em Ensino de Ciências, Águas de Lindóia. 
Martins, I. G. R., Gouvêa, G., Piccinini, C. (2005). Aprendendo com imagens. Ciência e Cultura, 57(4), 38-40.

Michinel, J. L. (2001). O funcionamento de textos divergentes sobre energia com alunos de física. A leitura no ensino superior. Tese (Doutorado) - FE, Unicamp.

Orlandi, E. P. (2010). Análise de discurso. Orlandi, E. P.; Lagazzi-Rodrigues, S. (Orgs.). Discurso e Textualidade. Campinas: Pontes.

Orlandi, E. P. (2003). Análise de discurso: princípios e procedimentos. Campinas: Pontes. Orlandi, E. P. (2006). Interpretação. Autoria, leitura e efeitos do trabalho simbólico. Campinas: Pontes.

Rego, S. C. R; Gouvêa, G. (2010). Imagens em materiais didáticos impressos para o ensino de física num curso de licenciatura semipresencial. Revista Brasileira de Ensino de Ciências e Tecnologia, 3 (3), 1-20.

RENN, J. (2004). A física clássica de cabeça para baixo: como Einstein descobriu a teoria da relatividade especial. Revista Brasileira de Ensino de Física, v.27, n.1, p. 27-36.

Sicard, M. (2000). Os paradoxos da imagem. Rua, 6, 25-36.

Silva, C. F. (2008). Construção e realidade nas imagens dos livros didáticos de física. Dissertação (Mestrado Profissional em Ensino de Física) - PUC/MG.

Silva, C. F., Martins, M. I. (2008). A iconicidade em livros didáticos de física. XI Encontro de Pesquisa em Ensino de Física, Curitiba, PR.

Silva, C. M. L. F. (2006). Uma proposta para o ensino da Teoria da Relatividade Especial no Nível Médio. Dissertação (Mestrado), Programa de Pós-Graduação em Ensino de Ciências Naturais e Matemática, UFRN.

Silva, H. C. (2002). Discursos escolares sobre gravitação newtoniana: textos e imagens na física do ensino médio. Tese (Doutorado) - FE, Unicamp.

Silva, H. C. (2006). Lendo imagens na educação científica: construção e realidade. ProPosições, 17(1), 71-83.

Silva, H. C.; Zimmermann, E.; Carneiro, M. H. S.; Gastal, M. L.; Cassiano, W. S. (2006). Cautela ao usar imagens em aulas de ciências. Ciência \& Educação, 12, 219- 233.

Souza, L. H. P.; Rego, S. C. R.; Sousa, G. G. (2010). A imagem em artigos publicados no período 1998-2007 na área de Educação em Ciências. Ensaio - Pesquisa em Educação em Ciências, 12(3), 85-100.

Souza, T. C. C. (2001). A análise do não verbal e os usos da imagem nos meios de comunicação. Rua, 7, 65-94. 
Wittgenstein, L. (1958). Philosophical investigations. New York: Macmillan.

Zimmermann, E., Evangelista, P. C. Q. (2004). Leitura e Interpretação de Imagens de Física no Ensino Fundamental. IX Encontro Nacional de Pesquisa em Ensino de Física, Jaboticatubas.

Recebido em: 27 de Fevereiro de 2020 